\title{
PARAMETRIC MARCINKIEWICZ INTEGRALS ON THE WEIGHTED HARDY AND WEAK HARDY SPACES
}

\author{
HUA WANG
}

Abstract. Let $0<\rho<n$ and $\mu_{\Omega}^{\rho}$ be the parametric Marcinkiewicz integral. In this paper, by using the atomic decomposition theory of weighted Hardy and weak Hardy spaces, we will obtain the boundedness properties of $\mu_{\Omega}^{\rho}$ on these spaces, under the Lipschitz condition imposed on the kernel $\Omega$.

Mathematics subject classification (2010): 42B25, 42B30.

Keywords and phrases: Parametric Marcinkiewicz integrals, weighted Hardy spaces, weighted weak Hardy spaces, Lipschitz condition, $A_{p}$ weights, atomic decomposition.

\section{REFERENCES}

[1] S. S. Aliev And V. S. Guliev, Boundedness of the parametric Marcinkiewicz integral operator and its commutators on generalized Morrey spaces, Georgian Math. J., 19 (2012), 195-208.

[2] A. Benedek, A. P. Calderón And R. PAnzone, Convolution operators on Banach space valued functions, Proc. Nat. Acad. Sci. USA, 48 (1962), 356-365.

[3] Y. Ding, M. Y. LeE And C. C. Lin, Fractional integrals on weighted Hardy spaces, J. Math. Anal. Appl, 282 (2003), 356-368.

[4] Y. Ding, M. Y. LeE And C. C. Lin, Marcinkiewicz integral on weighted Hardy spaces, Arch. Math, 80 (2003), 620-629.

[5] Y. Ding, S. Z. LU AND S. L. SHAO, Integral operators with variable kernels on weak Hardy spaces, J. Math. Anal. Appl, 317 (2006), 127-135.

[6] Y. Ding, S. Z. Lu And Q. Y. XuE, Marcinkiewicz integral on Hardy spaces, Integr. Equ. Oper. Theory, 42 (2002), 174-182.

[7] Y. Ding, S. Z. LU AND Q. Y. XUE, Parametrized Littlewood-Paley operators on Hardy and weak Hardy spaces, Math. Nachr, 280 (2007), 351-363.

[8] Y. Ding, S. Z. Lu AND Q. Y. XuE, Parametrized area integrals on Hardy spaces and weak Hardy spaces, Acta Math. Sinica, 23 (2007), 1537-1552.

[9] Y. Ding, S. Z. LU AND K. YABUTA, A problem on rough parametric Marcinkiewicz functions, J. Austral. Math. Soc, 72 (2002), 13-21.

[10] Y. DING AND X. F. WU, Weak Hardy space and endpoint estimates for singular integrals on space of homogeneous type, Turkish J. Math, 34 (2010), 235-247.

[11] Q. Q. FANG AND X. L. SHI, Estimates for parametric Marcinkiewicz integrals in BMO and Campanato spaces, Appl. Math. J. Chinese Univ. Ser. B, 26 (2011), 230-252.

[12] C. FEFFERMAN, N. RiviÈrE AND Y. SAGHER, Interpolation between $H^{p}$ spaces: The real method, Trans. Amer. Math. Soc, 191 (1974), 75-81.

[13] R. FEFFERMAn And F. Soria, The space weak $H^{1}$, Studia Math, 85 (1987), 1-16.

[14] J. Garcia-Cuerva, Weighted $H^{p}$ spaces, Dissertations Math, 162 (1979), 1-63.

[15] J. Garcia-Cuerva And J. L. Rubio De Francia, Weighted Norm Inequalities and Related Topics, North-Holland, Amsterdam, 1985.

[16] L. HÖRMANDER, Estimates for translation invariant operators in $L^{p}$ spaces, Acta Math, 104 (1960), 93-140.

[17] M. Y. LEE, $H_{w}^{p}$ boundedness of Calderón-Zygmund type operators, Commun. Math. Anal, 9 (2010), $77-83$. 
[18] M. Y. LEE AND C. C. LIN, The molecular characterization of weighted Hardy spaces, J. Func. Anal, 188 (2002), 442-460.

[19] M. Y. LEE, C. C. Lin And W. C. YAnG, $H_{w}^{p}$ boundedness of Riesz transforms, J. Math. Anal. Appl, 301 (2005), 394-400.

[20] J. F. Li AND S. Z. LU, Strongly singular integral operators on weighted Hardy space, Acta Math Sinica, 22 (2006), 767-772.

[21] C. C. LIN AND Y. C. LIN, $H_{w}^{p}-L_{w}^{p}$ boundedness of Marcinkiewicz integral, Integral Equations Operator Theory, 58 (2007), 87-98.

[22] H. P. LiU, The weak $H^{p}$ spaces on homogeneous groups, Lecture Notes in Math, Vol. 1494, SpringerVerlag, 1991, 113-118.

[23] H. P. LIU, The wavelet characterization of the space Weak $H^{1}$, Studia Math, 103 (1992), 109-117.

[24] S. Z. Lu, Four Lectures on Real H $H^{p}$ Spaces, World Scientific Publishing, River Edge, N.J., 1995.

[25] B. Muckenhoupt, Weighted norm inequalities for the Hardy maximal function, Trans. Amer. Math. Soc, 165 (1972), 207-226.

[26] T. S. QUEK AND D. C. YANG, Calderón-Zygmund-type operators on weighted weak Hardy spaces over $\mathbb{R}^{n}$, Acta Math. Sinica, 16 (2000), 141-160.

[27] M. SakAmoto And K. Yabuta, Boundedness of Marcinkiewicz functions, Studia Math, 135 (1999), 103-142.

[28] S. SATo, Remarks on square functions in the Littlewood-Paley theory, Bull. Austral. Math. Soc, 58 (1998), 199-211.

[29] X. F. SHI AND Y. S. JiAng, Weighted boundedness of parametric Marcinkiewicz integral and higher order commutator, Anal. Theory Appl, 25 (2009), 25-39.

[30] E. M. SteIn, On the functions of Littlewood-Paley, Lusin and Marcinkiewicz, Trans. Amer. Math. Soc, 88 (1958), 430-466.

[31] E. M. Stein, M. H. TAIBlEson AND G. WEISs, Weak type estimates for maximal operators on certain $H^{p}$ classes, Rend. Circ. Mat. Palermo, Suppl. 1, 2 (1981), 81-97.

[32] J. O. Stömberg And A. Torchinsky, Weighted Hardy spaces, Lecture Notes in Math, Vol. 1381, Springer-Verlag, 1989.

[33] X. X. TAO, X. YU AND S. Y. ZHANG, Marcinkiewicz integrals with variable kernels on Hardy and weak Hardy spaces, J. Funct. Spaces Appl, 8 (2010), 1-16.

[34] A. Torchinsky And S. L. Wang, A note on the Marcinkiewicz integral, Colloq. Math, 60/61 (1990), 235-243. 